\title{
Arabic Emphatics: Phonetic and Phonological Remarks
}

\author{
Majed Al-Solami \\ Department of Linguistics, University of Toronto, Toronto, Canada \\ Email: majed.al.solami@mail.utoronto.ca
}

Received July $24^{\text {th }}, 2013$; revised August $26^{\text {th }}, 2013$; accepted September $4^{\text {th }}, 2013$

Copyright (C) 2013 Majed Al-Solami. This is an open access article distributed under the Creative Commons Attribution License, which permits unrestricted use, distribution, and reproduction in any medium, provided the original work is properly cited.

\begin{abstract}
Arabic has a set of complex coronals, $/ \underline{\mathrm{s}} /, / \mathrm{d} /, / \underline{\mathrm{d}} /$ and $/ \mathrm{t} /$, which are the emphatic sounds of their plain counterparts $/ \mathrm{s} /, / \mathrm{d} /, / \mathrm{\delta} /$, and $/ \mathrm{t} /$. These emphatic sounds in Arabic are problematic both phonetically and phonologically. Phonetically, the secondary articulation of these sounds is disputed. Phonologically, they are grouped with the rest of Arabic guttural class in some studies while excluded by others. This paper touches on these arguments and argues that phonologically, these sounds are not part of the Arabic guttural class.
\end{abstract}

Keywords: Arabic Emphatics; Gutturals; Phonetics; Phonology

\section{Introduction}

Arabic has a set of complex coronals, $/ \underline{\mathrm{s}} /, / \underline{\mathrm{d}} /, / \underline{\mathrm{d}} /$ and $/ \underline{\mathrm{t}} /$, see Table 1. These sounds are said to be the emphatic sounds of their plain counterparts $/ \mathrm{s} /, / \mathrm{d} /, / \mathrm{d} /$, and $/ \mathrm{t} /$. The literature on Arabic emphatics shows a number of challenges, both phonetically and phonologically.

Phonetically, while it is agreed that emphatic consonants articulation involves a coronal articulation, analyses of the secondary articulation varies from one study to another. Researchers have posited that emphatics are velarized (Trubetzkoy, 1969), uvularized in Jordanian Arabic (Zawaydeh, 1998) or pharyngealized in Iraqi Arabic (Ali \& Daniloff, 1927; Gianni \& Pettorino, 1982).

Phonologically, some proposals group Arabic emphatic sounds with Arabic gutturals, laryngeals / $\mathrm{P}$ and $\mathrm{h} /$, pharyngeals /S and $\mathrm{h} /$ and uvulars / $\mathrm{s}$ and $\mathrm{x} /$, Jakobson, 1957; Zawaydeh, 1999, while other proposals posit them as a different subclass, McCarthy 1994, Bin-Muqbil 2006.

The aim of this paper is to provide phonological evidence that shows that Arabic emphatics should be excluded from Arabic Guttural Natural Class.

This phonological evidence is then extended to phonetic evidence to see whether emphatics can be excluded from Arabic Guttural Natural class phonetically as well. This is achieved by investigating the tongue shape and movement during the articulation of pharyngeals, uvulars and emphatics reported in the literature. Laryngeals are excluded from this study since they do not have any supraglottal constriction of their own.

Another aim of this paper is to examine current phonological representations of Arabic emphatics and gutturals in the light of the phonological and phonetic evidence provided in this paper.

\section{Phonetics and Phonological Representation}

The first position states that there is no relationship between phonetics and phonology. This view sees that each has a dif- ferent representation with no mapping between them (Fudge, 1967; Foley, 1977).

The second view indicates that the two should be discussed under a unified model where phonetics and phonology have a direct mapping (Flemming, 1995; Hayes, 1997).

The last view is between the other two positions. It considers phonetics and phonology as two separate fields, yet they are connected to one another (Keating, 1988; Anderson, 1981).

In this paper, the position taken is that experimental phonetic methods play an important role in verifying formal phonological representations. Such a view is beneficial in investigating the question of whether emphatic sounds in Arabic are part of the guttural class or not. This approach is manifested in what is called Laboratory Phonology. Kingston (2007) indicates that phonetics interfaces with phonology in three domains. First, distinctive features are defined using phonetic terms. Second, many phonological patterns have phonetic grounding. Third, phonological representations are needed for phonetic research. Ohala (1990) explains that phonetics and phonology are needed in any study of language to complement each other rather than being independent. He characterizes phonology as the mental representations of knowledge that speakers have about language and phonetics as the implementation of control signals from the phonological component. Because phonetics and phonology are closely related, Ohala suggests using the term integration rather than the term interface. He gives the follow-

Table 1.

Arabic emphatics, their plain counterparts and gutturals phoneme chart.

\begin{tabular}{|c|c|c|c|c|c|}
\hline & Dental & Alveolar & Uvular & Pharyngeal & Glottal \\
\hline Plosives & & $\begin{array}{l}\mathrm{t} \\
\mathrm{d} \\
\underline{\mathrm{t}} \\
\underline{\mathrm{d}}\end{array}$ & $q$ & & ? \\
\hline Fricatives & $\begin{array}{l}\text { ð } \\
\underline{\partial}\end{array}$ & $\begin{array}{l}\mathrm{S} \\
\underline{\mathrm{s}}\end{array}$ & $\begin{array}{l}x \\
\text { в }\end{array}$ & $\begin{array}{l}\hbar \\
\mathrm{c}\end{array}$ & $\mathrm{h}$ \\
\hline
\end{tabular}


ing benefits of including phonetics and phonology in language study. First, integrating phonetics and phonology in language study achieves simplicity. This can be reached by accounting for phonological processes phonetically. One example he provides is accounting for stop devoicing and the affrication of stops before high closed vowels using aerodynamic factors. Second, phonological hypotheses can be tested empirically if phonetics and phonology are integrated. Ohala indicates that no postulation in phonology that is undoubtable. Therefore, it is good to further investigate assumptions in phonology phonetically.

\section{Phonological and Phonetic Evidence for Arabic Guttural Class}

In the phonology of the Holy Quraan, referred to as Tajweed henceforth, laryngeals / $\mathrm{P}$ and $\mathrm{h} /$, pharyngeals / $\mathrm{S}$ and $\mathrm{h} /$ and uvulars /в and $\mathrm{x} /$, behave as a natural class. They undergo a process called Piðhar in Tajweed tradition. In this process, a nasal $/ \mathrm{n} /$ does not assimilate if followed by any of these six sounds, see Table 2 for examples. This is referred to as distinct pronunciation by Gouda (1988). He states that the nasal $/ \mathrm{n} /$ is articulated fully and clearly in this process. This process occurs within the same word and across word boundaries. Although ?iohar is a process cited from Classical Arabic, it is found in some Arabic dialects such as in Sudanese Arabic (Hamid, 1984).

Emphatic sounds and uvular /q/, on the other hand, undergo a different process in Tajweed if preceded by a nasal $/ \mathrm{n} /$, as can be seen in Table 3. This process is called Pixfaa. This process takes place when the tongue does not quite touch the alveolar ridge, and the vocal cavity holding the shape of the preceding vowel and the total sound articulated through the nasal cavity, (Gouda 1988). As in Piðhar, Pixfaa occurs within the same word and across word boundaries.

Another evidence for the natural class of gutturals in Arabic is given by McCarthy $(1991,1994)$. McCarthy, citing Green-

Table 2.

Examples of ?iðhar from Tajweed.

\begin{tabular}{cc}
\hline PIn huwa (53:4) & "it is no less than" \\
\hline Panfamta $(1: 7)$ & "those whom Thou hast favored" \\
fasayun & "Then will they shake their heads" \\
yanPawana (6:26) & "avoid" \\
yanhitun (15:82) & "they used to hew out dwellings from the hills" \\
Palmunxaniqah (5:3) & "the animal that has been strangled"
\end{tabular}

Table 3.

Examples of ?ixfaa from Tajweed.

\begin{tabular}{|c|c|}
\hline $\min$ qarar $(14: 26)$ & "possessing no stability" \\
\hline $\min \underline{\operatorname{tin}}(23: 12)$ & "an essence of clay" \\
\hline mandud (56:29) & "clustered" \\
\hline rifan sarsara (41:16) & "raging wind" \\
\hline ðilā óalila (4:57) & "We shall make them enter a dense shade" \\
\hline
\end{tabular}

Note: The numbers between brackets in Tables 3 and $\mathbf{4}$ refer to chapter and verse numbers in the Holy Quraan. berg (1950), indicates that in Arabic there is a tendency to prohibit the occurrences of roots that contain two guttural sounds, as in ${ }_{E m} \zeta$. This restriction does not apply to roots that have a guttural sound and an emphatic one, as in $\underline{t} m \varphi$ "greed", nor does it apply to roots that have guttural sounds and uvular $/ \mathrm{q} /$ as in $q m \mathcal{C}$ "suppression". Cases where emphatics and the uvular/q/ co-occur with a guttural sound are found in Arabic as in $q \underline{t} S$ "cut".

Another argument for excluding emphatics from Arabic guttural class is illustrated by the avoidance of gutturals in syllable final position in Arabic dialects. In Bedouin Hijazi Arabic, /? and $\mathrm{h} /$, pharyngeals $/ \mathrm{S}$ and $\mathrm{h} /$ and uvulars / $\mathrm{s}$ and $\mathrm{x} /$ are prohibited form coda position while emphatic sounds and uvular /q/ are allowed in this position. An underlying word of the form CVGCV, where $\mathrm{G}$ is a guttural, surfaces as CGV.CV with metathesis as in a-f in Table 4. In examples g-j in Table 4 uvular /q/ and emphatics occur in coda position.

\section{Articulatory and Phonetic Exponents of Emphatics, Uvulars and Pharyngeals}

The articulation of Arabic pharyngeals, uvulars and emphatics involve a general property of tongue retraction. However, the general shape and movement direction of the tongue are different in the following studies. Generally speaking, pharyngeals retract tongue root independently, while uvulars and emphatics retract tongue root as a result of tongue body retraction in general. These two different movements have different acoustic consequences.

The articulation of emphatic consonants involves a coronal articulation and a secondary articulation involving the back of the tongue. Analyses of the secondary articulation vary from one study to another. It is accepted, however, that the secondary articulation is a result of the retraction of the tongue body (Ali \& Daniloff, 1972).

Similar to emphatics, uvulars retract tongue body in general (Catford 1977). So, it seems that the main articulator in these sounds is the tongue body and tongue root retraction in these two sets is a result of tongue body retraction. Tongue root does not retract independently in these sounds, which is supported by the fact that these sounds have low F2 in adjacent vowels as their main acoustic cue rather than high F1 (Al-Ani, 1970).

Despite this similarity between them, uvulars and emphatics

Table 4.

Examples of metathesis in Bedouin Hijazi Arabic.

\begin{tabular}{|c|c|c|}
\hline a. /naS.dzah/ & [nSa.dzah] & "goat" \\
\hline b. /lah.mah/ & [lha.mah] & "piece of meat" \\
\hline c. /тав.rib/ & [твьа.rib] & "sunset" \\
\hline d. /rax.mah/ & [rqa.mah] & "coward" \\
\hline e. /gah.wah/ & [gha.wah] & "coffee" \\
\hline f. /sa?.lat/ & [s?a.lat] & "she asked" \\
\hline g. [?aq.rab] & & "nearer" \\
\hline h. [?it.laS] & & "come out" \\
\hline i. [?aō.rub] & & "I hit" \\
\hline j. [mas.lax] & & "slaughter house" \\
\hline
\end{tabular}


have some differences. The tongue body is depressed further during emphatics than uvulars. Also, uvulars have a more retracted tongue dorsum than emphatics (Ghazeli, 1977).

Pharyngeals are articulated with a retraction of the tongue root in the lower pharynx, (Ghazeli, 1977). As a result, acoustically, Arabic pharyngeals are associated with a high F1 in adjacent vowels (Al-Ani, 1970; Alwan, 1989). Also, tongue root movement in pharyngeals is independent, unlike that of uvulars and emphatics (Ghazeli, 1977).

From the discussion so far it is clear that Arabic emphatics cannot be excluded from Arabic Guttural Class articulatorily, however the phonetic differences highlighted in this section have some implications on the phonological representations of Arabic gutturals and emphatic sounds, as shown in the following section.

\section{Feature Geometry Representations of Emphatics}

To see how emphatics are represented in recent feature geometry studies, two proposals are included in the discussion; which are (McCarthy 1994) and (Zawaydeh 1999). The reason for including the work of (McCarthy 1994) is because it is a pioneering work that has been followed by a number of similar works and discussions. Zawaydeh's work is one of the few works that implement a modern method to investigate articulatory and acoustic properties of Jordanian Arabic.

\section{First Proposal}

McCarthy (1994) agrees that Arabic gutturals present a problem for articulator theory because they are articulated in different regions of the pharynx. As a result, he forms the feature [pharyngeal] to refer to their place of articulation rather than their common articulator. To McCarthy, this feature includes all the sounds articulated in the region from the larynx to the oropharynx. So, as he indicates, the acoustic cue of these sounds is a high F1, which is thus the acoustic cue for all gutturals. The feature [pharyngeal] identifies secondary articulation found in emphatic sounds as well, see the feature tree suggested by McCarthy (1994) given in Figure 1.

As shown in Figure 1, guttural sounds would avoid co-occurring within the same root as a result of the projection of the feature [pharyngeal].

Emphatics have the feature [pharyngeal] as their secondary articulation, which is achieved by constricting the pharynx.
a. Low gutturals ?hћৎ
b. Uvular gutturals $\underline{\mathrm{xH}}$

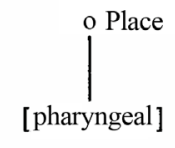
c. Coronal emphatics TDSZ
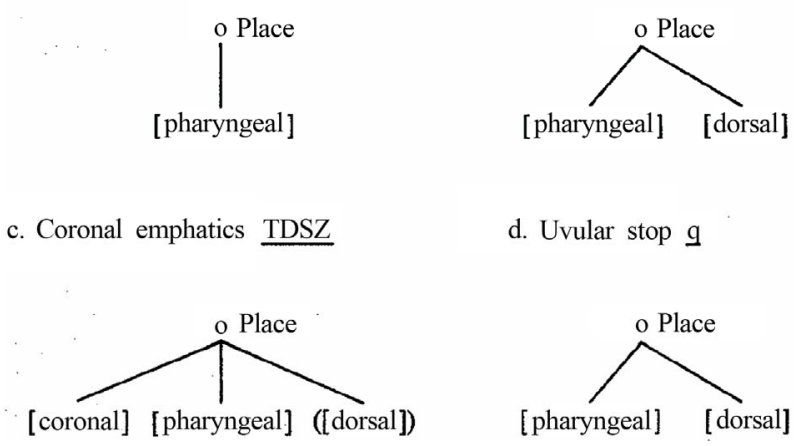
d. Uvular stop $g$

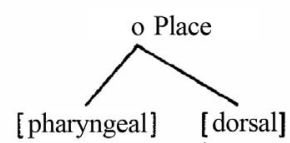

Figure 1.

McCarthy's feature geometry proposal (1994:221).
Also, [dorsal] is included in the representation of uvulars and emphatics to account for the fact that they are articulated with tongue dorsum retraction. McCarthy concludes that emphatics are uvularized due to the acoustic similarity between uvulars and emphatics. The feature [dorsal] is between parentheses to suggest that this feature is redundant for emphatics and not part of their underlying representation.

\section{Second Proposal}

Zawaydeh (1999), based on her articulatory and acoustic experiments, reports that every post velar sound in Jordanian Arabic is part of the Arabic Guttural Natural Class, which includes laryngeals, pharyngeals, uvulars and emphatics. She groups these sounds based on the fact that all of these sounds have a constriction in the pharynx except for laryngeals. Laryngeals are included based on a common acoustic cue, high F1, in all of these sounds, as she suggests. She asserts that uvulars and emphatics are articulated by retracting tongue dorsum to uvula region. As a result, she innovates the feature [Retracted Tongue Back] to use in the representations of uvulars and emphatics, as shown in Figure 2.

As can be seen in Figure 2, her proposal splits the place node into a lower vocal tract node (LVT) that dominates pharyngeals and laryngeals and an upper vocal tract node (UVT) that dominates oral features. She differentiates between primary place of articulation (1 place) and secondary place of articulation (2 place).

\section{Phonetic and Phonological Problems}

The representations of pharyngeals, uvulars and emphatics fail to account for some phonetic differences between these sounds. Also, these proposals cannot explain or account for some phonological processes discussed previously. These problems are discussed in this section.

These two proposals include a pharyngeal component to account for the fact that these sounds are articulated in the pharynx region. As explained previously, pharyngeals are articulated by tongue root retraction. This movement does not include any movement of any other part of the tongue. So, the active articulator in these sounds is the tongue root. Uvulars and emphatics, on the other hand, are articulated by movement of the entire tongue, no independent tongue root movement is observed.
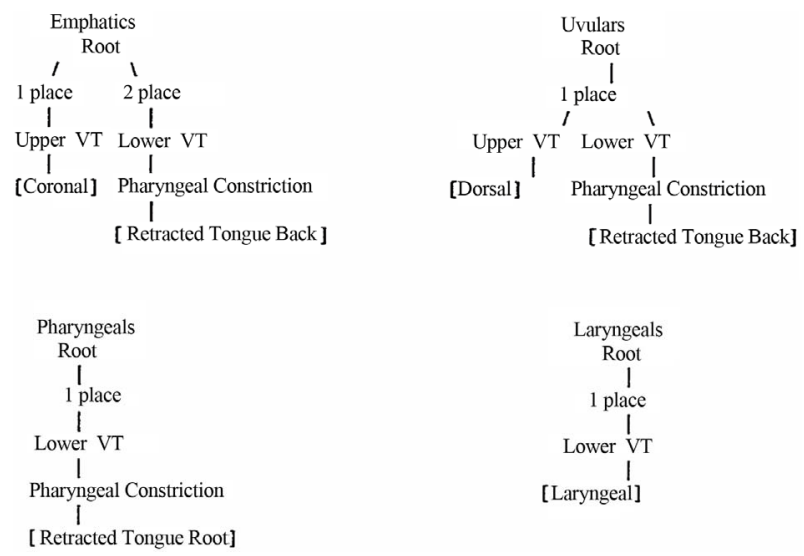

Figure 2.

Zawaydeh's feature geometry proposal (1999:82). 
Furthermore, the articulations of uvulars and emphatics are not the same. Tongue body is retracted further during emphatics and tongue dorsum is raised further during uvulars.

McCarthy (1994) acknowledges that emphatics and uvulars are articulated with tongue dorsum retraction, as suggested by the feature [dorsal]. However, he does not refer to this active articulator in emphatics, the feature [dorsal] is redundant in his proposal, rather he refers to the place of articulation [pharyngeal]. He includes the active articulator [dorsal] in the representation of uvulars, which gives the impression that uvulars and emphatics are different although he suggests that the secondary articulation in emphatics is uvularization.

Zawaydeh (1999) acknowledges the difference between emphatics and uvulars and pharyngeals. To account for this difference she proposes the feature [Retracted Tongue Back] for uvulars and emphatics and not for pharyngeals. The feature [Retracted Tongue Back], however, is not clear in the representation of uvulars. It is implemented twice in two different regions of the vocal tract, as the articulator of [dorsal] in upper vocal tract and the articulator for [Retracted Tongue Back] in lower vocal tract.

As discussed previously one of the phonological evidences for Arabic guttural class is OCP, where two guttural sounds do not co-occur within the same root. The two proposals account for this by including a terminal feature that is found in all guttural sounds. This feature is [pharyngeal] in McCarthy (1994) and (Lower Vocal Tract) in Zawaydeh (1999). As can be seen in Figures 1 and 2, these features are also found in the representation of emphatics. As a result, we expect that these proposals predict that emphatics would show the same co-occurrence restriction as other guttural sounds. However, emphatics and guttural sounds can co-occur within the same root without any restriction as discussed previously.

McCarthy (1994), to remedy this problem, includes the major class feature [approximant] in the representation. This would limit the OCP to guttural sounds which are approximants, unlike emphatics, as he suggests. However, Ladefoged and Madison (1996) indicate that not all Arabic guttural sounds are approximants. So, McCarthy's (1994) presupposition that all gutturals in Arabic are approximants is not accurate.

While she did not discuss this point in her thesis, I think that OCP problem can be accounted for in Zawayde's proposal by limiting the applicability of OCP to primary place of articulation (1 place) and not to secondary place of articulation (2 place). This proposal, however, would raise another problem. Velars and emphatics, although gradiently, show some co-occurrence restrictions. This restriction is the result of the secondary articulation in emphatics and not the primary coronal one. So, this proposal of limiting OCP to primary place of articulation does not hold for all sounds in Arabic.

This section discussed some phonetic and phonological problems of two feature geometry representations of emphatics in Arabic. These proposals fail to account for some phonetic facts and phonological processes found in Arabic.

\section{Conclusion}

This paper is motivated primarily by the analytical problems found in existing formal representations of Arabic emphatics and Arabic guttural class. Part of these inadequacies is a result of misunderstandings of the articulatory and phonological differences between emphatics and guttural sounds. This paper aims to highlight these problems found in feature geometry representations of these sounds by providing some insights of the articulatory and phonological behavior of Arabic emphatics and gutturals.

This paper also attempts to provide an argument for excluding Arabic emphatics from Arabic guttural class. To reach these points, the paper gives phonological evidence that shows that Arabic emphatics do not show similar phonological processes as the guttural class. Also, the paper seeks to find phonetic evidence to support this phonological patterning.

Future direction of this study is to provide an alternative formal representation that shows more understanding of the phonetic properties and phonological behavior of these sounds.

\section{REFERENCES}

Al-Ani, S. (1970). Arabic phonology: An acoustical and physiological investigation. The Hague: Mouton.

Ali, L. H., \& Daniloff, R. E. (1972). A contrastive cinefluorographic investigation of the articulation of emphatic-non-emphatic cognate consonants. Studia Linguistica, 26, 81-105. http://dx.doi.org/10.1111/j.1467-9582.1972.tb00589.x

Al-Nassir, A. (1993) Sibawayh the phonologist. London and New York: Keegan Paul International.

Alwan, A. (1989). Perceptual cues for place of articulation for the voiced pharyngeal and uvular consonants. Journal of the Acoustical Society of America, 86, 549-556. http://dx.doi.org/10.1121/1.398234

Bin-Muqbil, M. (2006). Phonetic and phonological aspects of Arabic emphatics and gutturals. Ph.D. Dissertation, Madison, WI: University of Wisconsin.

Catford, J. C. (1977). Fundamental problems in phonetics. Edinburgh: University Press.

Delattre, P. (1971). Pharyngeal features in the consonants of Arabic, German, Spanish, French, and American English. Phonetica, 23, 129-155. http://dx.doi.org/10.1159/000259336

Foley, J. (1977). Foundations of theoretical phonology. Cambridge: Cambridge University Press.

Fudge, E. C. (1967). The nature of phonological primes. Journal of Linguistics, 3, 1-36.

Ghazeli, S. (1977). Back consonants and backing coarticulation in Arabic. Ph.D. Dissertation, Austin, TX: University Texas at Austin.

Giannini, A., \& Pettorino, M. (1982). The emphatic consonants in Arabic. Speech Laboratory Report IV, Napoli: Istituto Universitario Orientale di Napoli.

Gouda, A. (1988). Quraanic recitation: Phonological analysis. Ph.D. Dissertation, Washington, DC: Georgetown University.

Hamid, A. (1984). The phonology of Sudanese Arabic. Ph.D. Dissertation, Urbana, IL: University of Illinois.

Jakobson, R. (1957). Mufaxxama-The emphatic phonemes in Arabic: synchronic and diachronic aspects. In: E. Pulgram (Ed.), Studies presented to Joshua Whatmough (pp. 105-115). The Hague: Mouton.

Kingston, J. (2007). The phonetics-phonology interface. Paul de Lacy (ed.), The handbook of phonology (pp. 401-434). Cambridge: Cambridge University Press.

Ladefoged, P., \& Maddieson, I. (1996) The sounds of the world's languages. Oxford: Blackwell Publishers.

Laufer, A., \& Baer, T. (1988). The emphatic and pharyngeal sounds in Hebrew and Arabic. Language \& Speech, 24, 39-61.

McCarthy, J. (1994). The phonetics and phonology of Semitic pharyngeals. In P. Keating (Ed.), Phonological structure and phonetic form: Papers in laboratory phonology III. Cambridge: Cambridge University Press. http://dx.doi.org/10.1017/CBO9780511659461.012

Ohala, J. J. (1990). There is no interface between phonetics and phonology. A personal view. Journal of Phonetics, 18, 153-171.

Trubetskoi, N. (1969). Principles of phonology. Berkeley: University of California Press.

Zawaydeh, B. (1997). An acoustic analysis of uvularization spread in 


\section{AL-SOLAMI}

Ammani-Jordanian Arabic. Studies in the Linguistic Sciences, 27, 185-200.

Zawaydeh, B. (1998). Gradient uvularisation spread in Ammani-Jordanian Arabic. In A. Benmamoun, M. Eid, \& N. Haeri (Eds.), Per- spectives on Arabic linguistics 11 (pp. 117-141). Amsterdam: John Benjamins,.

Zawaydeh, B. (1999). The phonetics and phonology of gutturals in Arabic. Ph.D. Dissertation, Bloomington, IN: Indiana University. 